\title{
BMJ Open Patient and general practitioner views of tools to delay diagnostic imaging for low back pain: a qualitative study
}

\author{
Adrian C Traeger (D) ,1,2 Juliet Checketts, ${ }^{3}$ Elise Tcharkhedian, ${ }^{4}$ \\ Denise A O'Connor, ${ }^{5,6}$ Christiane Klinner, ${ }^{1}$ Sweekriti Sharma (D) , ,2 Parima Vyas, ${ }^{3}$ \\ Loai Albarqouni, ${ }^{7}$ Kirsten McCaffery (1) ${ }^{2,8}$
}

To cite: Traeger AC, Checketts J, Tcharkhedian E, et al. Patient and general practitioner views of tools to delay diagnostic imaging for low back pain: a qualitative study. BMJ Open 2020;10:e039936. doi:10.1136/ bmjopen-2020-039936

- Prepublication history and additional materials for this paper are available online. To view these files, please visit the journal online (http://dx.doi org/10.1136/bmjopen-2020039936).

Received 29 April 2020 Revised 21 August 2020 Accepted 22 September 2020

Check for updates

(C) Author(s) (or their employer(s)) 2020. Re-use permitted under CC BY-NC. No commercial re-use. See rights and permissions. Published by BMJ.

For numbered affiliations see end of article.

Correspondence to Dr Adrian C Traeger; adrian.traeger@sydney.edu.au

\section{ABSTRACT}

Objective Delayed prescribing is a promising strategy to manage patient requests for unnecessary tests and treatments. The purpose of this study was to explore general practitioner (GP) and patient views of three communication tools (Overdiagnosis Leaflet, Dialogue Sheet and 'Wait-and-see' Note) to support delayed prescribing of diagnostic imaging.

Design Qualitative study.

Setting Primary and emergency care in Sydney, Australia. Participants 16 GPs and 14 patients with recent episode of low back pain.

Outcome Views on the tools to delay diagnostic imaging for low back pain. Data were collected using a combination of focus groups and individual interviews.

Analysis Two researchers independently performed a thematic analysis, and the author team reviewed and refined the analysis.

Results GP participants responded positively to the Overdiagnosis Leaflet. The Dialogue Sheet and 'Wait-andsee' Note raised several concerns about patient pushback, adding to time pressure and being overwhelmed with hard-to-find paper resources. GPs preferred to communicate verbally the reasons to delay an imaging test. For patients, the reactions to the tools were more positive. Patients valued written information and a signed agreement to delay the test. However, patients expressed that a strong desire for diagnostic imaging would likely over-ride any effect of written advice to delay the test. The term 'false alarm' to describe overdiagnosis was poorly understood by patients.

Conclusions GPs and patients agreed that a leaflet about overdiagnosis could support a delayed prescribing approach to imaging for low back pain. The Dialogue Sheet and 'Waitand-see' Note were acceptable to patients but not to GPs.

\section{INTRODUCTION}

Guidelines for low back pain recommend that clinicians reserve diagnostic imaging tests for patients who have clinical features of serious pathology. ${ }^{1}$ Yet on average general practitioners (GP) refer around a quarter of their patients with low back pain for imaging. ${ }^{2}$ In most cases these tests will not bring patients any benefit. ${ }^{3}$ Instead, overuse of imaging has
Strengths and limitations of this study

- Understanding how both general practitioners (GPs) and patients might use communication tools will help inform strategies to reduce overuse of diagnostic imaging.

- Our data collection methods allowed us to capture natural conversations in the focus groups and explore emergent themes in depth in the interviews.

- GPs included in this study were attending a professional education event and may have had more positive views of tools to delay imaging than the wider population of GPs.

negative consequences for the patient, the clinician and for health systems. ${ }^{4}$

A number of factors related to the patientclinician interaction could drive overuse of imaging for low back pain. A review of 17 qualitative studies identified 'perceived pressure from patients' as a key driver of guidelinediscordant imaging reported by doctors. ${ }^{5}$ Indeed, around $50 \%$ of patients with low back pain believe imaging is necessary. ${ }^{6}$ Also, many clinicians worry about medicolegal liability if they do not provide the test, and feel they lack tools to discuss the need for imaging with their patients. $^{7}$

Tools that promote watchful waiting as an evidence-based alternative to imaging could be effective at reducing overuse. For example, information leaflets to support delayed prescribing, that is, where a GP provides a script but instructs the patient to wait and see if symptoms resolve, can reduce use of antibiotics. ${ }^{8}$ One trial in the 1980s found this approach reduced imaging for low back pain. ${ }^{9}$ There is evidence that written delayed prescribing tools are acceptable to patients who are considering antibiotics and some screening tests. ${ }^{10}{ }^{11}$ However, it is unclear how GPs and patients might react to tools for symptomatic conditions where imaging overuse is problematic. 
In 2019 the Australian Government Department of Health developed a resource pack to support GPs as part of a broader programme of work to reduce unnecessary diagnostic imaging for musculoskeletal pain. The pack included three newly developed communication tools. One was developed by the lead author in collaboration with an advertising agency (Overdiagnosis Leaflet). The remaining two tools (Dialogue Sheet and 'Wait-and-see' Note) were developed by the Department of Health and with input from researchers and clinicians within the Wiser Healthcare Research Collaboration. The goal of the tools was to encourage discussions between patients and clinicians about the need for imaging and support a delayed prescribing approach to reduce unnecessary requests. Before deciding whether they would distribute the tools to GPs, the Department of Health commissioned a qualitative evaluation, which we describe here.

The aim of this study was to gather GP and patient views on the three newly developed communication tools to support delayed prescribing of imaging for low back pain.

\section{METHODS}

\section{Study design and participants}

We conducted a qualitative study with four focus groups and eight individual interviews to explore how GPs and patients understood and responded to the communication tools. We have prepared this report to adhere to the Consolidated criteria for Reporting Qualitative research checklist (see online supplemental appendix 1). ${ }^{12}$

We used convenience sampling to select participants. We aimed to conduct a minimum of two focus groups of at least five participants for each participant type. We planned additional 'mop-up' individual interviews which took place until saturation was reached. GPs who were practising in Australia were eligible to participate. For GP participants we recruited a sample of GPs who attended a continuing professional development event on 30 July 2019. Of the 23 GPs attending the event who were invited and eligible, 12 agreed to participate in a focus group. We recruited an additional four GP participants to participate in individual interviews, from a separate study. That study's aim was to explore GP perceptions of audit and feedback letters focused on diagnostic imaging for musculoskeletal conditions. After the interview about the audit and feedback letter intervention, GPs were invited to take the three tools away with them to use in their practice, for a period of 3 weeks (GPs in the focus groups were not given this opportunity). Because they were participating in a separate study, the four GPs who participated in individual interviews were aware of a broader programme of work to reduce unnecessary care by the Department of Health.

For the patient participants we recruited men and women who had sought care for low back pain between March and June 2019. We identified a consecutive list of adult patients who presented with 'non-serious' low back pain to the Emergency Department of Liverpool
Hospital, Sydney. Patient participants were approached using text messages from the hospital clinician and research team. Of the 40 patients who were invited and eligible, 10 agreed to participate in a focus group and 4 in an individual phone interview.

\section{Data collection}

The research team comprised a physiotherapist and research fellow (ACT); a PhD student with background in sociology (SS); two staff from the Department of Health (JC, PV); a senior physiotherapist (ET); a qualitative research assistant (CK); a GP and research fellow (LA); a senior research fellow (DAO); and an expert in qualitative research and professor of public health (KM). The focus groups were facilitated by ACT, SS, JC, PV and CK. The interviews were facilitated by CK, JC and DAO. The focus groups consisted of one male and three female facilitators. The interviewers (CK, JC, DAO) were female. ACT, JC and CK had experience with qualitative methods, including facilitating focus groups and interviews.

Researchers had no professional or ongoing relationship with the participants. Participants were informed that the researchers were interested in exploring the use of diagnostic imaging for musculoskeletal pain. The study was introduced to participants as an initiative to better understand the use of, and communication about, imaging for low back pain. Prior to beginning the sessions participants completed a written demographic questionnaire so that we could describe the sample. We asked all participants whether they agreed with the following statement: 'Everyone who gets low back pain should have an imaging test (x-Ray, CT, MRI)'. Patients were asked an additional question about their history of imaging for low back pain. GPs were asked questions regarding years of practice, their self-reported imaging rate and their interest in musculoskeletal conditions.

We audio-recorded all focus group discussions and interviews. The recordings were transcribed verbatim. Transcripts were not returned to participants for comment or correction. Facilitators made field notes throughout the interviews and identified salient themes. After the focus groups, the facilitators involved in the sessions (ACT, CK, PV, JC, SS, ET) independently documented their observations and emerging key themes. They then discussed these initial themes as a team.

\section{Focus groups}

Each group comprised five to seven people. The sessions had the following format: demographic questionnaire, introduction of study and facilitators, warm-up discussion, presentation of the tools (PowerPoint slides plus paper versions), and guided discussion of each tool (box 1). We held the sessions with GPs at the Institute for Musculoskeletal Health, a clinical research institute at the University of Sydney, on 30 July 2019. We held the sessions with patients at a 


\section{Box 1 Focus group and interview topic guide}

All participants.

- Participants take turns to read the tools and 'think aloud' as they read the content.

Which elements of the tools did you like? Why?

Which elements of the tools did you not like? Why?

- Do you have any suggestions for improvement?

For general practitioner participants.

Are any of these tools something that you would use? What would improve usability?

\section{For patient participants.}

- Did you gain any new information about imaging from these tools? If your doctor went through these tools with you, how would you feel? What would improve usability?

conference facility attached to Liverpool Hospital in Sydney on 23 August 2019. ET attended one of the patient focus groups as an observer. The focus group sessions lasted 60-90 min and had at least two facilitators from the author team.
Interviews

After the focus groups DAO and JC conducted additional individual interviews with four GPs, and CK conducted additional interviews with four patients. Interviews were conducted over the phone. We used these additional 'mop-up' interviews to further explore salient themes that emerged in the focus groups. We stopped recruiting patients for interviews when no new themes emerged (data saturation). ${ }^{13}$ Recruitment of GP participants for interviews was limited by resources and not necessarily by data saturation. The interview sessions lasted 20-40 min. No repeat interviews were carried out.

\section{Communication tools and discussion content}

Table 1 describes the rationale and content of the three communication tools. We selected these three tools because they were being used in a broader programme of work to reduce unnecessary diagnostic imaging by the Department of Health. Complete versions of the tools are included in online supplemental appendix 2. The focus groups and interviews followed a similar discussion format (box 1). The interview guide was not pilot-tested.

Table 1 Description and intended use of tools to support delayed prescribing of musculoskeletal imaging

\begin{tabular}{|c|c|c|c|}
\hline & Overdiagnosis Leaflet & Dialogue Sheet & Wait-and-see Note \\
\hline \multirow{2}{*}{ Why: rationale } & $\begin{array}{l}\text { Promote watchful waiting for } \\
\text { people with low back pain. }\end{array}$ & $\begin{array}{l}\text { Promote watchful waiting for people } \\
\text { with musculoskeletal pain (including low } \\
\text { back pain). }\end{array}$ & $\begin{array}{l}\text { Promote watchful waiting for people } \\
\text { with musculoskeletal pain (including } \\
\text { low back pain). }\end{array}$ \\
\hline & $\begin{array}{l}\text { Raise awareness of non-essential } \\
\text { or 'low-value' lumbar imaging } \\
\text { tests. }\end{array}$ & $\begin{array}{l}\text { Support doctor-patient communication } \\
\text { and joint decision-making. }\end{array}$ & $\begin{array}{l}\text { Support doctor-patient communication } \\
\text { and joint decision-making. }\end{array}$ \\
\hline
\end{tabular}

What: materials and content

\section{6-panel A4 folded leaflet}

Designed by advertising company and researchers.

Key messages

Unnecessary lumbar scans can cause harm.

\section{1-page A5 sheet}

Designed by the Department of Health and researchers.

\section{Key messages}

In your case I think imaging is unnecessary.

There are alternatives to imaging. I recommend we delay decision to have a scan.

\section{Tailoring: to the None.}

individual
Speak to your doctor.

\section{Behavioural prompts}

Framing of harms from overdiagnosis.

Appeal to authority (quote from orthopaedic surgeon)

There are other actions you can take to address your pain.

\section{Behavioural prompts}

Present no imaging as the default.

Co-signature (patient and doctor) commitment to delay.

Space to describe symptoms, things to look out for, name and date, customisable reasons to delay, and recommended actions to manage pain and assist recovery. 
Each started with a short warm-up discussion of the role of diagnostic imaging in low back pain. Participants were then presented with the three tools, in turn, for discussion.

\section{Data analysis}

Because this project worked to a strict timeline to meet Department of Health operational requirements, we chose to conduct focus groups primarily to capture the views of several participants in a short time frame.

We performed a thematic analysis to identify the main themes as well as divergent views. ${ }^{14}$ Our thematic approach focused on individual experiences and reactions arising from the data and across case comparisons. We started by analysing the focus groups first. Two authors coded the data from the focus groups (ACT, CK) using Microsoft Word and a third (SS) reviewed the transcripts and coding. The research team met to discuss the themes emerging from the focus groups and interpretation of the data. Key themes that the team agreed on were used to develop an initial coding framework for the data. These discussions of findings from the focus groups also led to refinement of the discussion guide for the individual interviews. We developed a library of codes in an iterative process, decided on a coding framework and applied this framework to the entire data set. A refined version of the coding tree is provided in box 2 . We used a 'constant comparison' approach, which involves continually looking for similarities, differences and other patterns within and across transcripts. ${ }^{15}$ Participants did not provide feedback on the overall findings.

\section{Patient and public involvement}

Patients and the public were not involved in the design or conduct of this study.

\section{RESULTS}

Sixteen GPs and 14 patients participated in the study. Table 2 shows the characteristics of participants.

Twelve GP participants were female and 13 had more than 20 years of practice. None of the GP participants agreed with the statement 'Everyone who gets low back pain should have an imaging test (x-Ray, CT, MRI)'. Thirteen GP participants reported requesting imaging in fewer than a quarter of their consultations for musculoskeletal imaging and eight had an interest in musculoskeletal conditions.

Eleven patient participants were born outside of Australia, 12 were between 20 and 60 years of age, and 6 had a university education or higher. All patient participants had had an imaging test in the past, and 11 believed everyone with low back pain should have imaging.

We summarise the key findings with selected quotes in the following sections. During the analysis the author team agreed that the clearest format to present the results was to present views of the two groups of participants separately. Additional supporting quotes (numbered in
Box 2 Summary of general practitioner (GP) and patient views on communication tools to support delayed prescribing of imaging for low back pain

\section{GP views.}

Reaction to Overdiagnosis Leaflet.

- Useful, visually appealing information.

- May increase anxiety and discourage necessary care.

- Digitise tools, communicate using other media in waiting room.

Reaction to Dialogue Sheet.

- Preference for verbal communication.

- Could add to time pressure.

- Reluctance to sign.

Reaction to Wait-and-see Note.

- Validating messages.

- Preference for verbal communication.

Workforce issues (all tools).

- Experienced GPs do not need these tools.

Concerns about patient pushback (all tools).

- Tools could undermine the patient-clinician relationship.

- Patients' (mis)interpretation of 'harms'.

Patient views.

Reaction to Overdiagnosis Leaflet.

- Authoritative, informative, reassuring, encourages discussion.

- Desire for less emphatic language.

- May increase anxiety, cause anger and discourage necessary care.

Reaction to Dialogue Sheet.

- Appreciated as a take-home tool/memory aid.

- Co-signed agreement could have mixed response.

Reaction to Wait-and-see Note.

- Uses dismissive terminology (eg, 'wait').

- Easily ignored.

Understanding and interpretation of content (all tools).

- Understood concept of overdiagnosis but were sceptical of its magnitude.

- Desire for clear definition of 'harm'.

- Struggled with terminology for false positives.

text as Q1, Q2, Q3 and so on) are provided in online supplemental appendix 3 .

\section{GP views}

Overall GP reactions

GPs had mixed reactions to the tools (box 2). Some GPs felt the communication tools could have a role in helping to manage difficult consultations:

I guess if you had a really stroppy patient you didn't know and didn't think you'd get any follow up with, perhaps there could be a role. (GP focus group)

However, most GPs reacted negatively to the Dialogue Sheet and Wait-and-see Note, and none of them reported they would use these in practice. They found the concept of written prompts and co-signing an agreement with their patient to be an insult to their clinical skill and autonomy: 


\begin{tabular}{lll}
\hline Table 2 & Participant characteristics $(\mathrm{N}=30)$ & \\
\cline { 2 - 3 } Characteristics & Participants (n) & \\
\cline { 2 - 3 } Patients $(\mathbf{n}=\mathbf{1 4})$ & GPs $(\mathbf{n}=\mathbf{1 6})$ \\
\hline $20-39$ & 5 & 2 \\
$40-59$ & 7 & 5 \\
$60-79$ & 2 & 9 \\
Sex & & \\
Female & 9 & 12 \\
Male & 5 & 4
\end{tabular}

Born outside of Australia

$\begin{array}{lrl}\text { Yes } & 11 & - \\ \text { No } & 3 & - \\ \text { University education } & & \\ \text { Yes } & 6 & - \\ \text { No } & 8 & - \\ \text { Had an imaging test for back } & 14 & - \\ \text { pain in the past } & & 0 \\ \begin{array}{l}\text { Believe everyone with low back } \\ \text { pain should have a scan }\end{array} & \\ \text { Years practising as a GP } & & \\ 1-9 & - & 2 \\ 10-19 & - & 13 \\ 20+ & - & 13\end{array}$

Self-reported imaging request rate

\begin{tabular}{ccc}
$<10 \%$ & - & 6 \\
$\sim 25 \%$ & - & 7 \\
$\sim 50 \%$ & - & 2 \\
$>75 \%$ & - & 1 \\
$\begin{array}{l}\text { Had an interest in management } \\
\text { of musculoskeletal conditions }\end{array}$ & 8 \\
\hline
\end{tabular}

GP, general practitioner.

No, no, I'd never use [the dialogue sheet] in a pink fit. (GP focus group)

GPs felt paper-based tools in general were impractical and easily forgotten, and preferred verbal reassurance:

Would I use [the dialogue sheet and note]? Probably not. I, probably again, I would document [instruction to delay] in the notes. I do document this sort of thing in the notes. (Female GP, 20+ years of experience)

GP reactions to the Overdiagnosis Leaflet: important content that would be useful in digital format, but may induce patient anxiety GP participants responded most positively to the design and content of the Overdiagnosis Leaflet. They valued the condition-specific information such as clinical features for lumbar imaging and self-management advice (Q1). Some felt the language of the leaflet was too emphatic and could discourage necessary imaging:
I mean [the overdiagnosis leaflet] would scare them off having a scan and maybe it might scare some of the $1 \%$ who do need to have it. (GP focus group)

GP participants expressed a strong preference for easily accessible, web-based or electronic medical record-based fact sheets for use with their patients $(\mathrm{Q} 2)$.

GP reactions to the Dialogue Sheet: redundant for experienced GPs, would add to time pressure

Most GP participants felt the Dialogue Sheet would be superfluous, and preferred to communicate the same messages verbally:

So, as I said, that's the sort of thing I would be telling the patient as we went, and maybe summarising at the end, but I would do that in a verbal fashion. I wouldn't be filling in a form like this. (GP focus group)

Some were concerned the tools would just add to time pressure within the consultation:

So, if the patient is going to have to sit down and read this, and try to understand it, and then sign it, it's just going to lengthen things out. It's just not going to be feasible. (GP focus group)

Most GP participants did not want to sign the Dialogue Sheet and felt that patients would be opposed to signing it as well:

It doesn't need a contract, we're not giving morphine out. (GP focus group)

GP reactions to the Wait-and-see Note: could help validate concerns, but impractical

One doctor noted that the language of the Wait-and-see Note could help validate a patient's experience:

I guess what the writer was trying to get across was: 'I acknowledge that you have real symptoms.' I think that's better, the patient wants me to know that they really have pain. (GP focus group)

A key barrier to use of the note was practicality. Participants felt verbal communication of similar messages would be more efficient (Q3).

Workforce issues and concerns about patient pushback (all tools) Some GP participants felt the communication tools were more useful for less experienced doctors or in the community more broadly (Q4):

This [overdiagnosis leaflet] is a document that absolutely needs to go [beyond] primary care level, at a community level. (GP focus group)

GPs felt the Dialogue Sheet and Wait-and-see Note would be patronising to patients or could compromise the clinician-patient relationship:

These pieces of paper are the opposite [to patient centered care], these are all giving me, the doctor, the 
power. And the patient is the person who's below me doing what I have told them. (GP focus group)

[If I were to use it with my patients] They'd probably think I've gone mad. (Female GP, 20+ years of experience)

\section{Patient views}

\section{Overall patient reactions}

Patients generally had positive reactions to all three tools (box 2). In contrast to GP responses, patients valued paper-based, written information and the perceived accountability that a co-signed agreement section on the Dialogue Sheet and Wait-and-see Note would provide:

I hate it when they don't keep their word to see you again. So this one, when they sign on it, they have to see you. (Patient focus group)

For some, the perceived benefit of locating the source of low back pain, and ruling out serious pathology, outweighed any advice to delay an imaging test (Q5). Others regarded the tools with suspicion:

I'm just now thinking maybe the doctors, the government, whatever, want all the people with the back pain not to do the scans any more. Why? (Patient focus group)

Patient reactions to the Overdiagnosis Leaflet: informative but alarming, prompts desire to discuss harms of imaging with GP Most patient participants found the Overdiagnosis Leaflet clear, informative and credible:

I'm assuming the quote comes from Professor Ian Harris at the bottom of the page. So yeah I think it's a fairly accurate statement, easy to understand, good advice. I guess it's clarified that he's an orthopaedic surgeon so that adds some weight to the comment. (Male patient, $40-59$ years old)

Some patients felt the Overdiagnosis Leaflet would encourage them to ask their doctor questions about their care (Q6). Other patient participants were reluctant to challenge the perceived authority of their doctor:

I just don't know if [my GP] would be comfortable hearing that from a patient. (Male patient, 20-39 years old)

There was concern among patient participants that the Overdiagnosis Leaflet would discourage imaging for those who did need it $(\mathrm{Q} 7)$. One patient participant reacted angrily to the concept that some scans might be unnecessary:

Telling me that a scan is not going to find something is a waste of my time. Not a waste of my time, but I'm angry as soon as I see it. I'm pissed off at that. (Patient focus group)
Patient reactions to the Dialogue Sheet: could improve recall of the consultation and provide evidence of GP commitment

In contrast to the Overdiagnosis Leaflet, which provoked some concerns, the Dialogue Sheet had potential to be reassuring. Patients had mixed reactions to the concept of co-signing an agreement to not have an imaging test; some felt it would be an odd process (Q8), where others appreciated the clinician's commitment:

$\ldots$ if he says he reviews us in two weeks, and he's signed it as well, if you come and he cancels it, it's on him. So it's peace of mind. (Patient focus group participant)

Patient reactions to the Wait-and-see Note: uses dismissive terminology and would be easy to ignore

Some patient participants found the concept of the Waitand-see Note dismissive. One patient participant, who was an allied health professional, felt patients might ignore the note:

I think, personally, people, if they've got the referral there, I think they would just ignore that [message to] wait-and-see. (Female patient, $40-59$ years old)

Patient understanding and interpretation of content (all tools): take care with language to describe overdiagnosis and related harms There was some suspicion among patient participants about the veracity of the data on the magnitude of overdiagnosis in the leaflet (Q9). One patient participant understood the link between overdiagnosis and unnecessary surgery, but felt the odds of this happening were not concerning:

...so only one will have surgery and they don't need it. So 1 out 100? [Facilitator: Yeah, not that bad do you reckon?]. Well yeah not that bad. (Patient focus group)

The term 'false alarm' was a poorly understood concept. Some patient participants felt the term indicated that their problem was imaginary $(\mathrm{Q} 10)$.

\section{DISCUSSION}

\section{Summary}

The GPs and the patients we interviewed had divergent views on the value of the three different communication tools to support delayed prescribing of imaging for low back pain. While almost all GPs rejected a tool with an example dialogue and discussion points, patients desired this process. Some patients appreciated the concept of co-signing an agreement to delay imaging, while others did not. The GPs we interviewed universally rejected this co-signing approach. There was variation in what patients and GPs considered to be a 'harm' from having imaging.

\section{Strengths and limitations}

We conducted this study at a time when advanced imaging rates are increasing. ${ }^{4}$ Understanding how both GPs and 
patients might use communication tools will help inform strategies to reduce this problem. We used a combination of focus groups and interviews and sampled people involved in the decision to have diagnostic imaging in emergency and primary care. This allowed us to capture natural conversations in the groups and explore emergent themes in depth in the interviews.

We were restricted to recruiting mainly from a GP professional development network, with a small number of additional participants recruited through an additional study. This group may have had more positive views than expected in the wider population of GPs, although our data suggest they were highly sceptical of the materials and divergent from patients. Unfortunately, none of the four GPs who offered to take the tools away could reflect on the use of the tools in practice, either because they did not see an appropriate patient in the 3-week period or because they forgot. This means that the views expressed here are restricted to hypothetical, rather than experiential, use of these tools. Although all of the patients we included had seen a GP for their low back pain, they had also attended the emergency department of a public hospital for their low back pain. This diverse group of patients may be different from those who typically attend a GP as their first or only contact with the health system. The patient participants in this study might also represent a group who take low back pain very seriously and be more critical of tools to delay or deter imaging.

\section{Comparison with existing literature}

Our findings are consistent with research showing that attempts to reduce or delay tests can arouse suspicion about financial arrangements, government oversight and motives to cut costs. ${ }^{16}$ This phenomenon also occurs in women considering breast cancer screening. ${ }^{17}$ Our study confirms that mistrust among patients could extend to communicating about delayed imaging, overdiagnosis and the option of watchful waiting.

We are aware of one other study that evaluated reactions to a communication tool to support GPs to reduce unnecessary imaging of low back pain. Jenkins $e a^{18}{ }^{18}$ examined GP and health consumer (community members with a history of low back pain) reactions to a booklet about lumbar imaging. Similar to our findings, some GPs preferred digital format, whereas health consumers appreciated a glossy hard copy to take home to discuss with their family. Health consumers valued detailed, written, individualised information and reassurance. Our findings suggest that patients may also desire tools that provide them with a sense that the GP has taken them seriously. The co-signed section in the Dialogue Sheet and Wait-and-see Note appeared to achieve this, yet GPs had reservations about using it.

Trials of patient-mediated interventions to reduce imaging rates have had limited success and suggest challenges to uptake. ${ }^{19}$ For example Schectman et a ${ }^{20}$ found no effect of patient education tools on imaging rates in their trial including 120 GPs, but only one-third of GPs reported using the tools in the trial. Given the divergent and sometimes strong views expressed in this study, ongoing evaluation of communication tools to meet the needs of end users appears essential.

The patients we interviewed reacted with surprise to the nature and magnitude of imaging overdiagnosis. Many of the patient participants struggled to think of harms of diagnostic imaging, other than exposure to radiation. This finding supports evidence on patient perceptions of overused screening tests, for example, the perception that the benefits of early detection tend to outweigh the harms of unnecessary tests. ${ }^{21}$ Our findings on how GPs describe harms from overdiagnosis suggest that they may also hold this view.

\section{Implications for future research and practice}

This study provides insights into the complexity of communicating about unnecessary imaging . Based on these findings there may be several ways to enhance acceptability and uptake of delayed prescribing approaches. First, the language relating to the necessity of diagnostic imaging tests should be cautious rather than emphatic. Patients may interpret harms differently; tools that describe risk of 'harms' would benefit from also providing clear examples of overdiagnosis. Second, tools should be in digital format for GPs, but readily printed for patients who prefer paper-based information. We may not have reached saturation on the key ways a GP might integrate communication tools into their workflow. Future research on how best to integrate delayed prescribing tools into workflow (eg, via access to leaflets, printed tear-off sheets, web-based or app-based tool, electronic medical record-based tools) would be informative for initiatives to reduce overuse. Finally, the Dialogue Sheet with or without a co-sign agreement section requires further testing before implementing this kind of tool in clinical practice. Together our findings suggest that an information leaflet that explains the problem of overdiagnosis could support a delayed prescribing approach to imaging for low back pain. The Dialogue Sheet and Waitand-see Note to help discuss delayed imaging may be acceptable to patients but not to GPs.

\section{Author affiliations}

${ }^{1}$ Institute for Musculoskeletal Health, The University of Sydney and Sydney Local Health District, Sydney, New South Wales, Australia

${ }^{2}$ School of Public Health, Faculty of Medicine and Health, The University of Sydney, Sydney, New South Wales, Australia

${ }^{3}$ Australian Government Department of Health, Canberra, Australian Capital Territory, Australia

${ }^{4}$ Department of Physiotherapy, Liverpool Hospital, Liverpool, New South Wales, Australia

${ }^{5}$ Monash Department of Clinical Epidemiology, Cabrini Institute, Malvern, Victoria, Australia

${ }^{6}$ Department of Epidemiology and Preventive Medicine, School of Public Health and Preventive Medicine, Monash University, Melbourne, Victoria, Australia ${ }^{7}$ Institute for Evidence-Based Healthcare, Bond University Faculty of Health Sciences and Medicine, Gold Coast, Queensland, Australia

${ }^{8}$ Sydney Health Literacy Lab, School of Public Health, The University of Sydney, Sydney, New South Wales, Australia

Twitter Adrian C Traeger @adrian_traeger, Sweekriti Sharma @SweekritiSharma, Loai Albarqouni @LoaiAlbarqouni and Kirsten McCaffery @KirstenMcCaffer 
Acknowledgements We thank Professor Chris Maher, Professor Rachelle Buchbinder and Professor Paul Glasziou for their valuable contributions to developing the tools and Luzian Ong for co-facilitating a focus group with GPs.

Contributors Study concept and design: ACT, JC, ET, DAO, CK, SS, PV, LA, KM. Acquisition of data: ACT, JC, ET, DAO, CK, SS, PV. Analysis or interpretation of data: ACT, JC, ET, DAO, CK, SS, PV, LA, KM. Drafting of the manuscript: ACT. Critical revision of the manuscript for important intellectual content: $A C T, J C, E T, D A O, C K$, SS, PV, LA, KM. Analysis: ACT, JC, ET, DA0, CK, SS, PV, LA, KM. Obtained funding: KM, ACT. Study supervision: ACT.

Funding Financial support for this study was provided entirely by a grant from the Australian National Health and Medical Research Council (NHMRC Program Grant APP1113532) entitled 'Using healthcare wisely: reducing inappropriate use of tests and treatments'. The funding agreement ensured the authors' independence in designing the study, interpreting the data, writing and publishing the report. DAO is supported by an Australian National Health and Medical Research Council (NHMRC) Translating Research into Practice Fellowship (APP1168749).

Competing interests None declared.

Patient consent for publication Not required.

Ethics approval Study procedures were approved by the University of Sydney HREC (ref: 2019/591), the Southwest Sydney Local Health District HREC (ref: 2019/ ETH00281) and the Bond University HREC (ref: LA03323).

Provenance and peer review Not commissioned; externally peer reviewed.

Data availability statement All data relevant to the study are included in the article or uploaded as supplementary information. No additional data are available.

This content has been supplied by the author(s). It has not been vetted by BMJ Publishing Group Limited (BMJ) and may not have been peer-reviewed. Any opinions or recommendations discussed are solely those of the author(s) and are not endorsed by BMJ. BMJ disclaims all liability and responsibility arising from any reliance placed on the content. Where the content includes any translated material, BMJ does not warrant the accuracy and reliability of the translations (including but not limited to local regulations, clinical guidelines, terminology, drug names and drug dosages), and is not responsible for any error and/or omissions arising from translation and adaptation or otherwise.

Open access This is an open access article distributed in accordance with the Creative Commons Attribution Non Commercial (CC BY-NC 4.0) license, which permits others to distribute, remix, adapt, build upon this work non-commercially, and license their derivative works on different terms, provided the original work is properly cited, appropriate credit is given, any changes made indicated, and the use is non-commercial. See: http://creativecommons.org/licenses/by-nc/4.0/.

\section{ORCID iDs}

Adrian C Traeger http://orcid.org/0000-0002-1646-1907

Sweekriti Sharma http://orcid.org/0000-0002-0919-8813

Kirsten McCaffery http://orcid.org/0000-0003-2696-5006

\section{REFERENCES}

1 Lin I, Wiles L, Waller R, et al. What does best practice care for musculoskeletal pain look like? eleven consistent recommendations from high-quality clinical practice guidelines: systematic review. $\mathrm{Br} \mathrm{J}$ Sports Med 2020;54:79-86.

2 Downie A, Hancock $\mathrm{M}$, Jenkins $\mathrm{H}$, et al. How common is imaging for low back pain in primary and emergency care? systematic review and meta-analysis of over 4 million imaging requests across 21 years. Br J Sports Med 2020;54:642-51.

3 Chou R, Qaseem A, Owens DK, et al. Diagnostic imaging for low back pain: advice for high-value health care from the American College of physicians. Ann Intern Med 2011;154:181-9.

4 Smith-Bindman R, Kwan ML, Marlow EC, et al. Trends in use of medical imaging in US health care systems and in Ontario, Canada, 2000-2016. JAMA 2019;322:843-56.

5 Slade SC, Kent P, Patel S, et al. Barriers to primary care clinician adherence to clinical guidelines for the management of low back pain: a systematic review and Metasynthesis of qualitative studies. Clin J Pain 2016;32:800-16.

6 Jenkins HJ, Hancock MJ, Maher CG, et al. Understanding patient beliefs regarding the use of imaging in the management of low back pain. Eur J Pain 2016;20:573-80.

7 Sears ED, Caverly TJ, Kullgren JT, et al. Clinicians' perceptions of barriers to avoiding inappropriate imaging for low back Pain-Knowing is not enough. JAMA Intern Med 2016;176:1866-8.

8 de Bont EGPM, Alink M, Falkenberg FCJ, et al. Patient information leaflets to reduce antibiotic use and reconsultation rates in general practice: a systematic review. BMJ Open 2015;5:e007612.

9 Deyo RA, Diehl AK, Rosenthal M. Reducing roentgenography use. Arch Intern Med 1987;147:141-5.

10 Bunten A, Hawking M. Patient information can improve appropriate antibiotic prescribing. Nurs Pract 2015

11 Emery JD, Pirotta M, Macrae F, et al. 'Why don't I need a colonoscopy?' A novel approach to communicating risks and benefits of colorectal cancer screening. Aust J Gen Pract 2018;47:343-9.

12 Tong A, Sainsbury P, Craig J. Consolidated criteria for reporting qualitative research (COREQ): a 32-item checklist for interviews and focus groups. Int J Qual Health Care 2007;19:349-57.

13 Bowen GA. Naturalistic inquiry and the saturation concept: a research note. Qualitat Res 2008;8:137-52.

14 Clarke V, Braun V, Hayfield N. Thematic analysis. Qualitative psychology: a practical guide to research methods, 2015: 222-48.

15 Pope C, Ziebland S, Mays N. Qualitative research in health care. analysing qualitative data. BMJ 2000;320:114-6.

16 Levinson W, Gorawara-Bhat R, Dueck R, et al. Resolving disagreements in the patient-physician relationship: tools for improving communication in managed care. JAMA 1999;282:1477-83

17 Hersch J, Jansen J, Barratt A, et al. Women's views on overdiagnosis in breast cancer screening: a qualitative study. BMJ 2013;346:f158.

18 Jenkins HJ, Moloney NA, French SD, et al. Using behaviour change theory and preliminary testing to develop an implementation intervention to reduce imaging for low back pain. BMC Health Serv Res 2018;18:734.

19 French SD, Green S, Buchbinder R, et al. Interventions for improving the appropriate use of imaging in people with musculoskeletal conditions. Cochrane Database Syst Rev 2010;1:CD006094.

20 Schectman JM, Schroth WS, Verme D, et al. Randomized controlled trial of education and feedback for implementation of guidelines for acute low back pain. J Gen Intern Med 2003;18:773-80.

21 Sutkowi-Hemstreet A, Vu M, Harris R, et al. Adult patients' perspectives on the benefits and harms of Overused screening tests: a qualitative study. J Gen Intern Med 2015;30:1618-26. 